\title{
Building management using information modeling technology
}

\author{
Fril Akhmetov*, Kamil Islamov, , and Sergey Sovkov \\ Kazan Federal University, 420008, Kazan, Russia
}

\begin{abstract}
The article presents an BIM implementation analysis in a context of Project management in the construction. Most efficient construction management process could be designed on most of PM branches, such as Project Supply Management, quality management in the project, Project Cost and Cost Management, Project Timing Management. The article presents the impact of GOST R 54869-201 "PROJECT MANAGEMENT REQUIREMENTS" on one of the most complicated environments, including BIM in construction. In Russia, much is said about supporting construction site project management; there are federal and regional programs of implementing BIM. There is also an understanding of what kind of construction design projects it is and why it is needed. There are many definitions of BIM design project detail level. Each region country has its own limitations and conditions for implementing BIM for construction project management. Another important aspect of implementing BIM opportunities in the regions is their isolation in the presented region and development will cause demand for local investments.
\end{abstract}

\section{Introduction}

The main task facing the management of a construction organization is the creation of an organizationally streamlined process of activities aimed at achieving the goals of the enterprise. The activity on the creation and reconstruction of construction objects is characterized by a high proportion of project orientation, for which the principles of project management are fully applicable.

Well known that project-oriented enterprises show much higher efficiency, are more mobile, less bureaucratic.

According to GOST $\mathrm{R}$ 54869-2011 REQUIREMENTS FOR PROJECT MANAGEMENT, Project management includes a set of processes for initiating, planning, organizing execution, monitoring and completing a project. Within the framework of project management processes, those actions are performed related to the following functional areas of project management:

\footnotetext{
* Corresponding author: $\underline{\text { akhmetov fril@,mail.ru }}$
} 
- Project Time Management;

- Project Cost Management;

- Project Risk Management;

- Project Human Resource Management;

- Project Stakeholders Management;

- Project Supply Management;

- Project Quality Management;

- Project Communications Management.

\section{Resource Management (Project Supply Management)}

Construction BIM Model is considered as a Digital Project of Work Production. This Digital Project allows high degree of detail and reliability of the project itself. in The construction BIM model's element-specific level of detailed description of each BIM element on a construction site provides next level of Implementation of project management principles.

Each BIM element specific construction site project planning provides a source data for Materials delivery schedule, planned up to the day. Daily detailed material delivery brings an opportunity to create more effective delivery schedules. Such efficient daily schedule for material delivery comes as a base for improving logistics efficiency.

Optimizing logistics and supplies itself does a great deal for further optimization of warehouses, and increases the share of installation "from wheels" - when construction element gets installed to designed placement right on the moment when it arrives to construction site.

\section{Quality control (quality management in the project)}

Management of quality is based on a quality control process - as an "element" of the BIM model. Each design-time BIM element is being re-interpreted as a single or multiple or part of construction-time BIM element.

This interpretation process is made by construction BIM engineers, as a part of planning for quality control work in digital PWP.

The steps for improving of the project management quality is designed during real-time executive documentation being written. For planning each BIM-element for each day schedule plan, elementary information about the executor and controlling persons are populated and implemented to global daily schedule.

Real-time quality monitoring also becomes available due to each BIM-element presence in a daily schedule. Using the element-specific basement for digital construction site BIMmodel provides an opportunity for real-time interface for fixing the Start and Finish time point of installing each construction BIM element.

\section{Cost management (Project Cost and Cost Management)}

BIM-designed construction site daily schedule requires every single BIM-element's cost of work. Element-specific cost fixation provides an information platform for real-time resource accounting.

High estimated cost forecast, which becomes one of possibilities, is based on Big-data analysis platform, which uses all available each BIM elements' cost-burn facts, saved on an enterprise own cloud platform. 
Persistence of enterprise level Big-data platform provides a source data for developing so-called Firm Element Costs (FESN in Russian abbreviature) - the real fixed costs of completed works

Technology and organization strategy is based on FESN, as a data source to design optimize technology and improve the cost-effectiveness of construction process and project management.

\section{Time Management (Project Timing Management)}

Most possible level of dualization - is a daily schedule, based on each BIM-element. Such detail planning level provides a planned by-element time schedule.

Element-specific time-schedule used for design Planning by detailing PWP using enterprise own statistics. Real-time data exchange interface comes for designing the actual production schedule.

Efficiency of Project timing management comes as a result of implemented Real-time elemental by-minute graph, which technically based on each BIM-element's model, which elements were tracked during start-stop event fixation.

Big-data, which is being produced on daily construction process, by each BIM elements' every event, afterwards implemented as a source for the elemental statistics of time really spent.

\section{Risk Management (Project Risk Management)}

BIM-based risk management principles have a potential for evolution and further optimization based on detailed operational element control. One of those detail information sources is a top-level detailed real-time information board, which provides a status display for each construction site's BIM-element

Another efficient increasing tool as an ability to monitor and analyze deviations for each BIM-element's event, based on a real-time data-exchange interface and dashboard.

To give a risk management process more flexibility, construction BIM-model provides realistically-taken BIM model modification, based on real-time events ingestion, fixed in an enterprise cloud platform.

All those improvements then totals as an availability to develop measures to compensate for failed deadlines, which also should be driven by real-time board of construction BIM model.

\section{Communication between participants (Project Information Exchange Management)}

Event-driven architecture of construction project management platform makes possible to have a Real-time information sharing functionality.

Besides an efficient information events real-time flow, it derives also an opportunity for personal level event logging, produces be identified BIM-element, which also saved and kept in a cloud infrastructure.

Functional sharing of information about each BIM-element adds more granular data source for decision making, and allows more flexible functionality for managing the flow of information. 
Personalized content of each BIM-element's event payload gives a point for developing and pushing personal alerts about relevant to each person events, most important for a given period of time.

Big-data information source of each BIM-elements, their events, personalized information belonging - all this bunch of data is being implemented as starting point for designing a functionality for responsibility control in the context of each construction BIMelement.

\section{Personnel management (Human resources management in the project)}

General evolutionary process of constant developing the efficiency of HR and managing personnel is enriched by new option: "Tomorrow's" outfit. Outfit for next day or couple of days, is designed by construction BIM engineer, and includes all outfits information to a global planning schedule.

Day Outfit (local daily planning) uses a target policy schedule deadline and each BIM element plans, combines all information and provides a comprehensive tool for construction site optimization strategy.

Human resource forecast starts building on top of most probable and detailed source data, and per-minute schedule design comes up with a powerful analysis of the effectiveness of personal performance of human resources.

\section{Components of successful BIM-based Project management}

To be able to design most possibly efficient construction BIM model for further implementing the principles of Project Mentadent, there should be prepared a set of requirements and conditions:

the presence of a high-quality design BIM model - for designing and populating construction BIM elements database;

- $\quad$ exclude unrealized design solutions, which are technically impossible, but affect global planning time schedule;

- $\quad$ train of hunt engineering competences in BIM Management - to have required HR for redesigning design BIM model to construction BIM model - this should be at least engineer with knowledge of BIM;

develop or install software and hardware implementation of Construction conveyor technology - the technical capability is provided by the appropriate software solution.

\section{Tomorrow Outfit Entity}

An example of using the capabilities of BIM technologies in optimizing the processes of organizational and technological management in contract construction can be considered on the example of the outfit of tomorrow.

At the same time, the "BIM Model" approved for production serves as the basis - it is unchanged, only in special cases the "BIM Release of the Project №_ from the date, month and year" is issued.

Undoubtedly, this Design Model requires a real "BIM Construction Model". In the future, it will grow into the "BIM Operational Model". It is no coincidence that the concept of BIM is used here - as "Technologies of the Information Model of Russian origin" 
The concept of "building element" as the main production indicator is not accidental. Let's take as an example - "production of brickwork wall-partitions" on a specific floor (level). It can be produced by a specific bricklayer brigade with the necessary provision of materials and other things necessary for production.

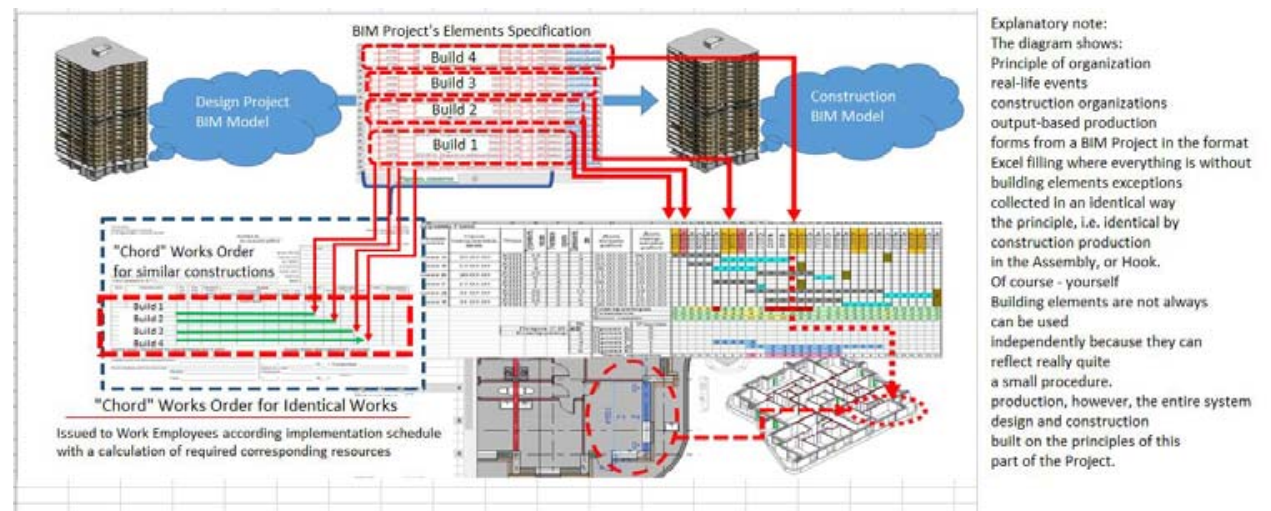

Fig.1. Tomorrow Outfit Source Elements

Another wall-partition at the same level requires additional bricklayers and provision of production or a certain execution time taking into account the execution of the previous one - if we decide to continue production with the same workers.

A designer and builder can manipulate only one "building element" at the time of production - this is an axiom that does not require any proof. For the simultaneous production of several "elements" additional resources are required - human, material and technical in the form of a computer device and software, for example, Revit, Bentley, Allplan, ArchiCAD, etc.

\section{Time-specific Target schedule}

In our case, a specific building element is produced according to the real "ID address of placement in the BIM model of the Project" transferred for unconditional placement on the construction site relative to the axes of the building, which are identical to the project coordinates only in nature.

Creation of construction products in accordance with the directive schedule with a real temporal indicator - (a quotation mark is not a separating slip, it is semantic, i.e. here is a concept for a certain time parameter) - where by the time of production, practically a certain time allotted for production - there are components and direct work manager.

It is not some kind of improvised tape that determines the process, but the very time of its production - a certain and set time by the schedule of construction production.

Directive schedule in this context comes as a target global deadline point of time, associated both with the very end of a Project itself, when construction of all BIM elements is finished, and also with a bunch of milestones, representing such key project changes, which serve as a beacon for designing the detailed process implementation schedule.

BIM engineering employee, which responsible for implementation of daily scheduled Tomorrow outfit filling, uses each such beacon as a target point in time schedule, to populate a such most possibly implementable works for Tomorrow, as possible to produce in available resources on than point in time. 


\section{Requirements for starting construction process}

The basic rule is that it is allowed to start production if there is an official document "Order for the construction production of a building element" and six mandatory parts of the production of a building under construction in the form of a" building element":

1. Materials and structures are within reach of crane production.

2. Responsible person - "a special service worker from materials and technologies supply at the construction site" transfers the components directly to the product manufacturer - the brigade in the presence of line personnel under an "electronic signature" the day before the start of production.

3. Line workers of the Construction Site organize the workplace of the manufacturer according to the Safety of his compliance.

4. The work must be done by qualified workers.

5. Acceptance of execution is carried out by the Customer - noting on the real "Virtual executive model of KS-2" where it confirms the production process - on this model only visual confirmation. This Model is executive - transmitted as "Executed" which corresponds to the standard of initial acceptance ".

6. The customer finally accepts the "building element" in accordance with the acceptance procedure in accordance with the established procedure for KS-3. As-built documentation and acts of acceptance of the "building element" are sent to the repository of "as-built documentation".

\section{Conditions for Successful Acceptance}

At the same time, the process itself has a clear and unconditional preparation of the construction process with the provision of the necessary resources, i.e. clear material and technical support - specifically materials, structures, components, and certainly the workers themselves of sufficient qualifications at the time of production at the "here and now" are present at the workplace.

The organizing document is the "Passport of the element", which is stored in a virtual storage in the form of a Construction Organization Project on the Construction Information Modeling Technology "Construction Organization Project - BIM of construction".

The contractual relationship between the customer and the contractors must be actually secured by the obligations issued by an official document in the construction industry in the form of "Order for work" with guaranteed obligations on the part of the enterprise - with a list of providing the necessary components by the production support service in the construction company.

\section{Deal conditions between Customer and Contractor}

The contractual relationship between the customer and the contractor must be actually secured by the obligations issued by an official document in the construction industry in the form of "Order for work" with guaranteed obligations on the part of the enterprise - with a list of providing the necessary components by the production support service in the construction company exactly the appointed time, provided by the process production.

Remuneration for labor is a special article of the contracting parties - however, it should not exceed the cost provided for in the estimate. 
The builder must take action to eliminate the non-conformity. If it nevertheless exceeds in this case, the Customer is called, who must decide to revise the price in the prescribed manner.

\section{BIM Element's Passport}
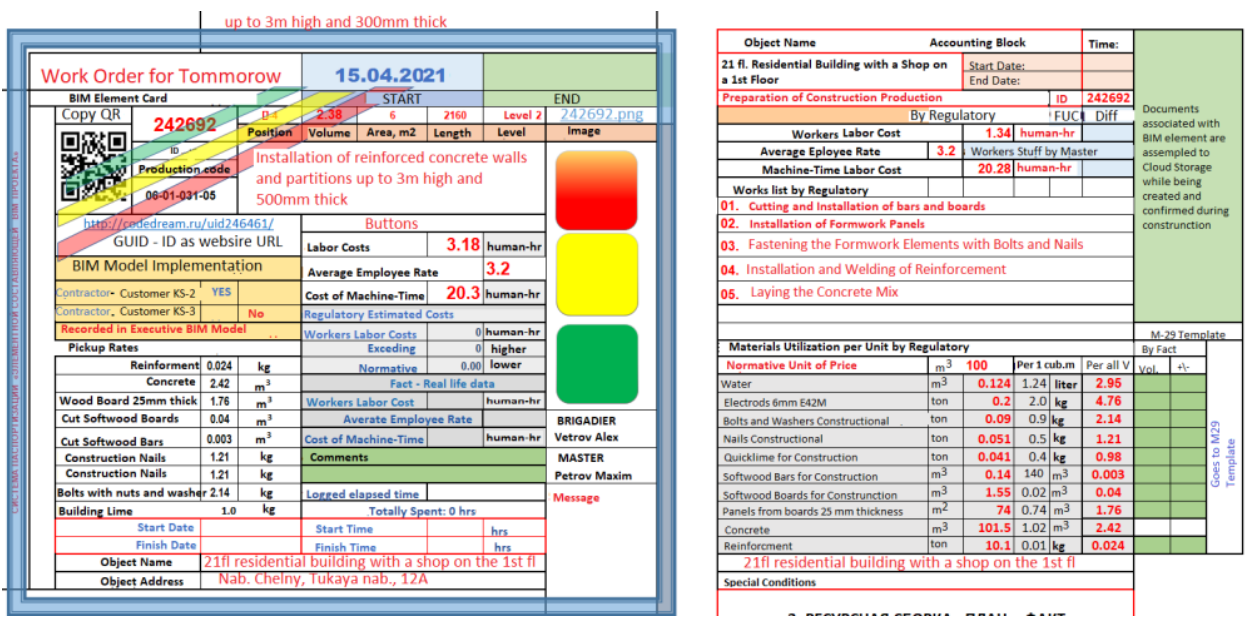

Fig.2. BIM Element's Passport

This "Outfit" based on a real-time information, collected right out of own company Data warehouse, and makes possible to proceed its BIM elements to implementation on construction site. The basis of the whole process is - "The outfit of tomorrow" provided with everything necessary for its production for a specific tomorrow.

Tomorrow outfit as BIM Element Passport should be the only one or part of the "Accordion outfit for the same identical works". Each outfit has a specific perplexed Responsibility person.

A person, who is responsible for

The outfit has two sections - "production order" and "normative block".

At the same time, this is not some kind of abstract outfit - but a task for the production of a concrete - real "building element" from which a building is assembled on a construction site in a strictly designated place - at a project address real by construction registration - let's call it "construction ID address".

In all circumstances, the assembly of elements into various formations - the basis is a specific element of the building for production - "here and now".

\section{Outfit as an Identified definition}

The definitely described fact is that "Outfit for Tomorrow" is not abstract - it is tied to a specific real "building element" or several elements - in a chord outfit tied to the principle of identity, ie. identical in production, but different in volume, located at a certain level of the building (floor).

Each "building element" has an individual registration address for the "project ID address" and with the operational mandatory "QR code", which points to Data Storage, associated with the necessary Info-data on their construction production stored in the data warehouse under the "Building Model Information Modeling Technology". 
This "code" is unique in relation to a specific "building element" and stores all information on this building element - the entire history from the Project - according to the "ID code - project" and according to the "ID code of its construction placement" and "QR associated code data on construction production ".

Thought, Tomorrow outfit, comes, first, as a strict sequence of detailly described actions, as a normatively designed works, scheduled by a close to minute sharpness, and second - as a exactly defined list of ID identifiers of BIM elements, situated at each one's construction site and target building's placement.

Such detailed scheduling of Tomorrow outfit based strategy of implementing all the project on a construction site comes to such principles of all the construction process, which could be compared to Conveyor at the car building plant.

\section{Conveyor Concepts for Construction BIM Model}

System basis: Real (interactive) "Passport of a building element".

A prerequisite for the successful work of the "BIM of conveyor" is the provision of production with Materials and Structures for the interactive "Outfit of Tomorrow" from the general "Accordion Order for Identical Work" tied to the "Operational Schedule of construction, ie. contractual - delivery real object"

Mapping is not some kind of invention - the entire system in mechanical engineering goes through the process of mapping specific products (elements) of production as a whole.

In the automotive industry, there are more than two hundred thousand such assemblies entering the conveyor.

The Boeing plane has up to eleven million elements - in mechanical engineering this practice is considered normal - in construction we can assume that the building is also assembled from its "elements".

For example, one of the Sports Complexes in Moscow had up to two hundred and forty thousand "building elements", taking into account the special assembly work and finishing.

The meaning of Conveyor principles for each BIM element as a part of BIM design project Construction model, comes with a connected information unit from BIM element itself to a Tomorrow outfit based detailed schedule. When BIM engineering construction site team has an access to both installation information of each exact element as well as point in time based sequential information, this allows each team member organize each workday as a strict sequence of actions, which one should do, finding oneself at a required place on a site, equipped with all necessary equipment, constructions and materials.

When BIM engineering team gets built-in for the global conception of Conveyor on a construction site, each moment of time they should be provided by a whole set of all the associated information, detailed for each corresponding BIM element. Such businesscritical information comes, in that way, a strong requirement of all the construction processes, as well as on a construction site, and at the engineer's office workstations.

To be able for managing such information flow, there should be a strict rules documentation set, more similar to a single point of truth, available for each implementing construction element. Though, designing such information flow system, performing as a unified structure atomic based mechanism, requires a base information unit elementary structure, which could serve a core starting point of all the remaining associated information flows.

Such core information element should, first, be associated to each BIM element entity, as BIM element is a key principle for all the conception, and second - should bring a 
valuable and physically describable set of information. And such elementary information core entity - is a BIM element Passport.

\section{BIM Element Passport Concepts}

Practically, "Passports" are generated from the "BIM Construction Database" in the "Passports." format, where all the initial data is stored in this data warehouse. The process of filling with data and the "Passport" itself with filling with data must be formally programmed.

Information about a specific "building element" can be viewed in a specially created interactive document in the form of an "Element passport".

Data, which is required for populating building element's view, is dynamically calculated based on information system logic. For calculating each significant parameter, BIM element logic, besides using exact data from database, could also apply real-time analysis formulas, aggregations and forecasting formulas for probable future values.

The first immediately imagination of this - is a certain card index - however, in physical form, presented on the page of this presentation. There is a certain "Matrix of the Passport" in which, at the request of the user, filling with data is carried out, which then participate in the process of use.

In fact, this is the source of all calculations that occur during the BIM of Preparation for Construction Production.

\section{Element's Passport Concepts}

The process of "Certification of all elements" involved in the formation of the building is one of the most important factors in the real and high-quality process of preparing construction production

This method can be compared with the concept of "mapping" ie. the creation of "technological information maps for a particular product" which is practiced in industrial production.

If the "building element" has unconditional - identical production processes (the same), but different sizes and, accordingly, volumes, and placement at a certain Level (floor) - it is possible to combine them into some "assemblies of identical works" (hereinafter "Assemblies").

In the context of construction site, these are grabs, complexes, nodes, etc. which create the prerequisites for organizing construction production in the prescribed manner.

The process of processing the selected "building element" in terms of specific filling with the necessary data, in particular, as specified materials and structures, is also solved in the same way - organizing the output information on the "building element."

\section{Conclusions}

Practically, the software 3D product of the design process is built on an unconditional elemental basis where all data can be stored in a specially created "elementary library of the software product" by means of which "BIM Construction Model" will be formed in the process of preparing construction production.

Wide usage of Big Data, Data Warehousing, Data Engineering, Machine Learning technologies, applied to own data, ingested from each even tiny data source, makes a good point for efficient automation processes, as well as building convenient tools for 
engineering and management company resources. Construction BIM Conveyor concepts, powered by BIM Element Entity based Detailed Schedule management - is a key element for generating most valuable Data, associated to each construction element, and detailed information about that element's each spent dollar and minute.

The term used by us "Passport of a building element" is a kind of interactive document, i.e. - this is a set of data necessary for construction production, its belonging to a real construction product in the form of a "building element" with the conditions of execution on time and quality indicators.

In both design and construction, the "building element" appears everywhere - this is the main entity involved and the main subject to which attention should be directed - to the rest of the processes that are all connected with these "building elements" serve as the basis for the formation of initial - organizing data for the main process - for its production at a specific ID address of its location in the Project and at the construction site itself.

Thus, introducing the concept "Passport of a building element" created on the basis of the ID of a building element and "BIM Construction Model" built on the principles of the classical school of construction management but at a higher quality and detalization level, in terms of management functions, having the ability to fill the "Passport of a building element" with various with the data necessary for project management and organization of the construction process, we get the opportunity to implement the principles of project management in all main types of functional areas in accordance with GOST R 54869-201 "REQUIREMENTS FOR PROJECT MANAGEMENT"

\section{Acknowledgments}

The work is performed according to the Russian Government Program of Competitive Growth of Kazan Federal University.

\section{References}

1. Code of rules SP 301.1325800.2017 "Information modeling in construction. Rules for the organization of work by production and technical departments." (approved by the order of the Ministry of Construction and Housing and Communal Services of the Russian Federation of August 29, 2017 N 1178 / pr).

2. O.I. Pakidov, BIM Basics: Information Modeling for builders. An article in the online resource http://isicad.ru/ru/articles/Pakidov/BIM-building-book-3.pdf

3. L.V. Gabdullin, K.F. Islamov, I.M. Khamitov, Small construction business: problems and solutions (Naberezhnye Chelny, Tatarstan, Russia), AD Alta - Journal of Interdisciplinary Research 9, 23-25 (2019)

4. K.F. Islamov, D.A. Khalikov, The structure of the information model of the classification system of thermal insulation materials, Basic research 7, 40-45 (2016)

5. E.S. Sibgatullin, K.F. Islamov, Determination of the bearing capacity of homogeneous plates and shells under multi-cycle loading, Basic research 6, 107-111 (2016)

6. K.F. Islamov, L.V. Gabdullin, I.M. Khamitov, Small construction business: problems and solutions (russia, republic of tatarstan, naberezhnye chelny), AD ALTAJOURNAL OF INTERDISCIPLINARY RESEARCH 9(2), 23-25 (2019) 
7. D.A. Khalikov, K.F. Islamov, The structure of the information model of the classification system of heat-insulating materials, Basic Research 7-1, 40-45 (2016) http://www.fundamental-research.ru/ru/article/view?id=40455.

8. A.V. Bataev, A.A. Gorovoy, A.B. Mottaeva, Proceedings of the 32nd International Business Information Management Association Conference, IBIMA 2018 - Vision 2020, 102-114 (2018) 